\title{
Actualidad del campesinado y los pueblos originarios en Argentina: entre el reconocimiento estatal y la territorialidad dissidente
}

\author{
Diego Domínguez ${ }^{1}$
}

\section{Resumen:}

Distinguimos que en las últimas décadas de Argentina, en un contexto de rearticulación de los patrones de acumulación capitalista en el agro, se ha dado un ascenso de la conflictualidad rural y la emergencia de territorialidades campesinas e indígenas, que resisten los procesos de despojo y se proponen el acceso a la tierra y el control de los bienes naturales en términos comunitarios y/o cooperativos, reivindican modalidades tecnológicas alternativas al paradigma de la agricultura industrial, y proponen otra relación entre el campo y la ciudad. En este trabajo específicamente pretendemos delinear estas territorialidades y caracterizar su actualidad frente a los cambios de gobierno que se presentan en continuidad y ruptura con el periodo anterior.

Campesinado - Pueblos Originarios - Territorialidades - Conflictualidad - Tierra

\section{Resumo:}

Identificamos nas últimas décadas da Argentina, num contexto de rearticulação dos padrões de acumulação capitalista na agricultura, a ocorrencia de um aumento da conflitualidade rural e o surgimento de territorialidades camponesas e indígenas que resistem aos processos de expropriação e procuram o acesso à terra e o controle dos recursos naturais comunitariamente, afirmam métodos tecnológicos alternativa ao paradigma da agricultura industrial, e propõem uma outra relação entre o campo ea cidade. Neste artigo pretende-se delinear especificamente estas territorialidades e caracterizar o seu presente de encontro às mudanças do governo que ocorrem em continuidade e descontinuidade com o período anterior.

Campesinato - Povos Indígenas - Territorialidades - Conflictualidade - Terra

\section{Abstract:}

We distinguish that in the last decades of Argentina, in a context of rearticulation of the patterns of capitalist accumulation in agriculture, there has been an increase in rural conflict and the emergence of peasant and indigenous territorialities, which resist the processes of dispossession and propose access to land and control of natural assets in community, demand alternative technological modalities to the paradigm of industrial agriculture, and propose another relationship between the countryside and the city. In this paper we specifically intend to delineate these territorialities and characterize their current situation in the face of the changes of government that present themselves in continuity and rupture with the previous period.

Peasantry - Indigenous peoples - Territoriality - Conflictuality - Land

\footnotetext{
${ }^{1}$ Sociólogo, doctor en Ciencias Sociales de la Universidad de Buenos Aires (UBA), Argentina. Investigador del IIGG-CONICET. Profesor de Sociología Rural (catedra Giarracca) y titular de Ecología Política, en la UBA.
} 


\section{Contexto histórico de la cuestión campesina e indígena en Argentina}

En Argentina se observa, con el regreso del régimen democrático de mediados de la década de 1980, la aparición de sujetos políticos ligados a la producción del espacio ${ }^{2}$ en áreas rurales, conceptualizados también como movimientos socioterritoriales, a partir de una identidad campesina o en base a un profundo proceso de etnogénesis que ha reinstalado la cuestión de los pueblos originarios en la agenda pública.

Estas presencias están fuertemente ligadas con el recrudecimiento de la conflictualidad por la tierra en Argentina, sin olvidar la gestación de un modelo agrario alternativo (basado en la agroecología, la soberanía alimentaria y la reforma agraria), como así la consolidación de un nuevo corpus de derechos colectivos en el país (el derecho indígena y el ambiental). El escenario agrario que enmarcó la emergencia de tales realidades ha sido definido como modelo de agronegocios, un tipo de reordenamiento de los sistemas agroalimentarios y agroindustriales que sucedió, vía disciplinamiento social y cambios de políticas públicas, al modelo anterior que algunos autores han denominado “agroindustrial” (Giarracca y Teubal $\left.{ }^{3}\right)$.

De modo que en el cruce del despliegue de la intensificación agrícola y el ascenso de reivindicaciones socioterritoriales en clave campesina e indígena, situamos nuestro interés de análisis. En los frentes de avance (regiones extrapampeanas) la demanda empresarial de nuevos espacios para la producción agropecuaria, fundamentalmente de exportación, se encuentra con unas poblaciones rurales que se posicionan desde la condición campesina o indígena, y que persisten a partir de una emergencia política ${ }^{4}$ anclada en el derecho a la tierra y al territorio con acciones directas, administrativas y legales, reivindicando sus modos de vida en interacción con unos ecosistemas singulares

\footnotetext{
${ }^{2}$ LEFEBVRE, Henri. The production of space. Oxford: Blackwell. 1991 [1974].

${ }^{3}$ GIARRACCA, Norma y TEUBAL, Miguel. "Del desarrollo agroindustrial a la expansión del 'agronegocio': el caso argentino”. En: Bernardo Mançano Fernandes (org.). Campesinato e agronegócio na América Latina: a questao agrária actual. Sao Paulo. Clacso (Ed). 2008.

${ }^{4}$ En línea con las consideraciones de Jacques Ranciere la política está ligada a una ruptura en la lógica del orden de lo visible y lo decible, de los procedimientos establecidos, los roles y posiciones definidas, es la aparición de un sujeto nuevo, allí donde no se consideraba presencia y enunciado alguno. La política como distorsión de la dominación naturalizada, a partir de la institución de una existencia donde no la había, como proceso de subjetivación que produce "escenarios paradójicos", instalando la contradicción. Ver: RANCIERE, Jacque. El desacuerdo. Política y Filosofía. Buenos Aires. Ed. Nueva Visión. 1996.
} 
(Chaco Húmedo y Seco, Alta Cuenca del Río Bermejo, Humedales del Pilcomayo, Puna, Estepa y Bosques Patagónicos, Selva de Yungas, Esteros del Iberá, Selva y Delta Paranaense, Monte de Sierras, Bolsones y Mesetas centrales, etc) (Burkart et al, en Brown, Martínez Ortiz, Acerbi y Corcuera ${ }^{5}$ ).

Por un lado la presión proveniente de la demanda empresarial de nuevas tierras para producciones cerealeras y ganaderas, y por otro la presión de poblaciones rurales que reivindican derechos campesinos o ancestrales ligados a su condición de pueblo originario, y se resisten a abandonar sus posesiones históricas o ancestrales, o bien ocupan y recuperan nuevas tierras. En efecto, se asiste a la "doble presión” sobre la tierra, que adquiere mayor magnitud según cada provincia, y va delineando una creciente conflictividad por el control de los recursos naturales (Gómez ${ }^{6}$; Barbetta y Domínguez ${ }^{7}$ ). El punto crítico de esta convergencia se expresa fundamentalmente como disputa por la tierra. Desde la década de 1990 en adelante, en el país se registra un aumento sostenido de la conflictividad por la tierra y los bienes naturales en general, sobre todo en zonas con población rural (Domínguez ${ }^{8} ; \operatorname{REDAF}^{9}$ ).

En el marco de tal conflictualidad, distinguimos en Argentina actualmente diversos patrones de apropiación de la tierra y el espacio entre las poblaciones rurales que se identifican como campesinas o se reconocen como parte de pueblos originarios. Entendemos que en las últimas décadas, en contexto de rearticulación de los patrones de acumulación capitalista en el agro, se ha dado la emergencia de territorialidades campesinas e indígenas. En este trabajo específicamente una pregunta que nos guía es en qué condiciones las poblaciones rurales despliegan territorialidades que se proponen el

\footnotetext{
${ }^{5}$ BROWN, A., U. MARTINEZ ORTIZ, M. ACERBI Y J. CORCUERA. La Situación Ambiental Argentina 2005. Buenos Aires. Fundación Vida Silvestre Argentina. 2006.

6 GÓMEZ, César. Conflictos por el acceso a la tierra en la provincia de Chaco. Nuevas territorialidades derivadas de la reestructuración productiva. En: Actas de VI Jornadas de Investigación y Debate Territorio, Poder e Identidad en el Agro Argentino, Instituto de Investigaciones Geohistóricas-CONICET. Resistencia, 21, 22 y 23 de mayo. 2009.

${ }^{7}$ BARBETTA, Pablo y DOMINGUEZ, Diego. Recreación comunitaria del campesinado en la interfase socio-jurídica. Ponencia presentada al V Congreso Argentino y Latinoamericano de Antropología Rural, marzo 2013, La Pampa: Núcleo Argentino de Antropología Rural ISBN 978-950-863-192-3.

${ }^{8}$ DOMINGUEZ, Diego. La lucha por la tierra en Argentina en los albores del Siglo XXI. La recreación del campesinado y de los pueblos originarios, Tesis doctorado, Ciencias Sociales de la Universidad Buenos Aires. 2009. Disponible en: http://lanic.utexas.edu/project/laoap/iigg/tesis6.pdf. Acceso 05/02/2017.

${ }^{9}$ REDAF - Red Agroforestal Chaco Argentina. Conflictos sobre tenencia de tierra y ambientales en la región del Chaco argentino: $3^{\circ}$ Informe. 1a ed. Reconquista. Ed REDAF. 2013.
} 
acceso a la tierra y el control de los bienes naturales en términos comunitarios y/o cooperativos, reivindican modalidades tecnológicas alternativas al paradigma de la agricultura industrial, y proponen otra relación entre el campo y la ciudad.

Nuestra hipótesis de trabajo sería la siguiente. La conflictividad por la tierra en Argentina expresa la emergencia de al menos dos procesos: por un lado la existencia o gestación de territorialidades disidentes en relación a la monopolización del espacio agrario por el capital, y por otro lado, separado solo en términos analíticos, una programática agraria y agroalimentaria alternativa, basada en la soberanía alimentaria (como organización de las relaciones entre actores agrarios y entre el campo y la ciudad) y en la agroecología (como conjunto de practicas productivas). Para abordarla, en primer lugar haremos un recorrido por la conflictualidad por la tierra en Argentina. Luego, nos acercaremos a la experimentación social implicada en las territorialidades ligadas al campesinado y los pueblos originarios de Argentina. Finalmente, en base a los debates y aportes analíticos anteriores, abordamos la actualidad de estas realidades sociales en Argentina (año 2016).

\section{Giro ecológico-territorial de la conflictualidad por la tierra}

El "Grito de los Juríes" de $1986^{10}$ (que parece rememorar el levantamiento de los chacareros arrendatarios de 1912, llamado "Grito de Alcorta"), y luego la "Carpa Negra de la Simona" en $1998^{11}$, ambos hechos dieron origen al Movimiento Campesino de Santiago del Estero (MOCASE), y allanaron el camino que instaló la cuestión campesina en la arena pública a escala nacional. A pesar de su menor visibilidad, también cabe destacar en esos mismos años los conflictos de tierra que surgen en la zona de Pampa del Indio y Colonias Unidas, en Chaco, que impulsarían la creación de la Unión de Pequeños Productores Chaqueños en 1985. A la par, pero con la singularidad de la cuestión indígena, comunidades kollas de Salta protagonizaban al final del siglo XX su segundo

\footnotetext{
${ }^{10}$ Movilización realizada el 29 de octubre de 1986, por más de 1500 campesinos por el derecho a la tierra y contra los desalojos, en la localidad santiagueña de Los Juríes. Esta acción colectiva fue catalizadora de un conjunto de experiencias que años después derivaría en la conformación del MOCASE en 1990.

${ }^{11}$ Instalación realizada por el MOCASE desde el 27 de octubre de 1998, para resistir a los desalojos de familias campesinas en esa localidad. Por la difusión y las adhesiones que recibió se tornó en símbolo de la resistencia campesina y su lucha por la tierra en Argentina.
} 
"Malón de la Paz" a Buenos Aires (en alusión al "Malón de la Paz" de 1946), para volver a reclamar su derecho ancestral a las tierras ${ }^{12}$.

Estos primeros conflictos por la tierra acabaron inaugurando un nuevo ciclo de disputas de este tipo en Argentina, ante la reactivación del avance de los frentes agropecuarios. En algunos casos los conflictos por tierra han implicado, además de un problema de titulación o de propiedad/tenencia/posesión, también la reivindicación de derechos colectivos sobre vastos espacios, múltiples pisos ecológicos, que en algunos casos escapan a las fronteras definidas por la configuración estatal del territorio. Emblemáticos en este sentido fueron los conflictos contra los grandes terratenientes y empresas, llevados a cabo por el activismo de las comunidades del pueblo Kolla de la alta cuenca del Río Bermejo, en Salta, reactivado con la vuelta de la democracia. En otros casos los conflictos por tierra involucraban la disputa sobre los usos del ambiente como las luchas de comunidades andinas de la Quebrada de Humahuaca o de vecinos de pequeñas ciudades como Esquel o Gualeguaychu contra megaemprendimientos mineros o industriales, o las luchas de pescadores y vecinos del Delta del Paraná contra mega proyectos inmobiliarios en las islas. Por otra parte, los análisis de tipo cualitativo fueron dando cuenta de los diversos lenguajes o de la semiótica de las luchas: la soberanía alimentaria, derecho posesorio, la preexistencia al Estado Nación, etcétera. Se pudo observar que en algunos casos se mantenían contenidos históricos como la "función social de la tierra", y en otros se anudaban a los argumentos tradicionales de "tierra para el que la trabaja" elementos novedosos como "la defensa del territorio ancestral".

El conjunto de conflictos ha ido en aumento en las décadas siguientes, y su alcance geográfico se ha extendido (Domínguez ${ }^{13}$; Barbetta $^{14}$; Gómez ${ }^{15} ; \operatorname{REDAF}^{16} ;$ MAGYP $^{17}$ ).

\footnotetext{
${ }^{12}$ Fue una "caravana" a Bueno Aires, para obligar al gobierno a recibirlos. Se trató de una acción colectiva que tuvo mucha difusión mediática, bautizada como aquella movilización similar de 1946 que se reuniera con el presidente Juan Domingo Perón. Un año después, en 1994, se incluyó en la Constitución Nacional el corpus de derechos de los 'pueblos originarios, en carácter de preexistentes al Estado Nación argentino. ${ }^{13}$ DOMINGUEZ, op cit.

${ }^{14}$ BARBETTA, Pablo. "En los bordes de lo jurídico: Campesinos y justicia en Santiago del Estero" en Cuadernos de Antropología Social, Buenos Aires, Facultad de Filosofía y Letras (UBA), 2010, №32.

${ }^{15}$ GÓMEZ, op cit.

${ }^{16}$ REDAF, op cit.

${ }^{17}$ MAGYP. Relevamiento y sistematización de problemas de tierra de los agricultores familiares en la Argentina. Andrea Gigena [et.al.]; dirigido por Karina Bidaseca. 1a ed. Buenos Aires: Ministerio de Agricultura, Ganadería y Pesca de la Nación, 2013. 96 p.; 30 x 21 cm.
} 
Protagonizan estos conflictos diversas poblaciones rurales, algunas identificadas con la condición campesina o indígena, aunque también se encuentran sectores que se reconocen como productores familiares, chacareros o colonos. Los estudios sobre tales conflictos también han puesto en evidencia otro conjunto de actores sociales involucrados. Se trata de productores capitalistas de diversas escalas o bien empresas involucradas en la producción agropecuaria, mayormente ligados a los procesos más dinámicos de actual modernización del campo, principalmente de expansión de los frentes sojero, ganadero o forestal, que se consolidó a partir de las políticas neoliberales orientadas al agro. Como mencionamos antes, a este nuevo patrón o lógica de organizar el campo y sus actores se le ha denominado agronegocio, y se lo considera parte de un proceso general de reprimarización de la economía, sostenido por el "consenso de los commodities", y de una modalidad de acumulación llamada extractivista o neo-extractivista (en función de la sobreexplotación de recursos naturales, expansión de las fronteras agropecuarias, etc) (Oesterheld ${ }^{18}$; Teubal, Dominguez y Sabatino ${ }^{19}$; Teubal $^{20}$; Pengue y Morello ${ }^{21}$; Viglizzo y Jobbagy ${ }^{22} ;$ Svampa $^{23}$ ).

Cuadro I: Los conflictos de tierra más destacados en el periodo post-dictadura a la actualidad $^{24}$, en Argentina, según región geográfica:

\begin{tabular}{|l|l|}
\hline Región geográfica con conflictos de tierra: & $\begin{array}{l}\text { Principales organizaciones y comunidades } \\
\text { afectadas o involucradas }\end{array}$ \\
\hline $\begin{array}{l}\text { Departamentos de Santiago del Estero: Alberdi, } \\
\text { Taboada, Atamisqui, Copo, Pellegrini, Moreno, } \\
\text { Figueroa, etc. }\end{array}$ & $\begin{array}{l}\text { Movimiento Campesino de Santiago del Estero - } \\
\text { MOCASE }\end{array}$ \\
\hline Alta cuenca del Río Bermejo: Salta y Jujuy & $\begin{array}{l}\text { Comunidades del pueblo Kolla, actualmente } \\
\text { organizadas en el Qullamarka. }\end{array}$ \\
\hline
\end{tabular}

\footnotetext{
${ }^{18}$ OESTERHELD, Martín. "Los cambios de la agricultura argentina y sus consecuencias". En Ciencia Hoy. Argentina. 2005. Vol. 15. № 87.

19 TEUBAL, Miguel, DOMINGUEZ, Diego y SABATINO, Pablo. "Transformaciones agrarias en la Argentina. Agricultura industrial y sistema agroalimentarios". En Giarracca, Norma y Teubal, Miguel (Coord). El campo argentino en la encrucijada, Buenos Aires, Alianza Editorial. 2005.

${ }^{20}$ TEUBAL, Miguel "Expansión del modelo sojero en la Argentina. De la producción de alimentos a los commodities". En Realidad Económica. Buenos Aires, IADE. Mayo-junio. 2006. № 220.

${ }^{21}$ PENGUE, Walter y MORELLO, Jorge "Procesos de transformación en las áreas de borde agropecuario: ¿Una agricultura sostenible?”. En Revista Biodiversidad. Disponible en: http://www.biodiversidadla.org/. Publicado el 26/10/2007.

${ }^{22}$ VIGLIZZO, Ernesto Francisco y JOBBAGY, Esteban. Expansión de la frontera agropecuaria en Argentina y su impacto ecológico-ambiental. Buenos Aires. Publicación del INTA. 2010.

${ }^{23}$ SVAMPA, Maristella. "Consenso de los Commodities» y lenguajes de valoración en América Latina", En Revista Nueva Sociedad No 244, marzo-abril de 2013, ISSN: 0251-3552.

${ }^{24}$ Este listado no pretende ser exhaustivo de los conflictos por tierra desde el fin de la dictadura al año 2010. Se mencionan los escenarios de conflictividad más significativos por: duración del conflicto, amplitud geográfica y poblacional, importancia organizativa.
} 


\begin{tabular}{|c|c|}
\hline Chaco salteño: Salta & $\begin{array}{l}\text { Comunidades de los pueblos originarios Wichí, } \\
\text { Chorote, Chulupí, Toba y Tapiete. Organizados } \\
\text { en Lhaka Honhat, entre otras. } \\
\begin{array}{l}\text { Organizaciones de familias criollas y } \\
\text { campesinas: OFC y APPCHS. }\end{array}\end{array}$ \\
\hline Regiones de Misiones: & $\begin{array}{l}\text { Comunidades Mbyá-Guaraní, de Yryapú. CCT, } \\
\text { MOCAMI, PIP, UTR, OPFAL, MAM, OPPES, } \\
\text { PUSALI, entre otras. }\end{array}$ \\
\hline $\begin{array}{l}\text { Región pampeana: Buenos Aires, Córdoba, Santa } \\
\mathrm{Fe} \text {, La Pampa. }\end{array}$ & $\begin{array}{l}\text { Movimiento de Mujeres Agropecuarias en Lucha } \\
\text { - MML }\end{array}$ \\
\hline Noroeste de Córdoba: & Movimiento Campesino de Córdoba - MCC \\
\hline Regiones de Chubut, Neuquén, Río Negro: & $\begin{array}{l}\text { Pueblo Mapuche: Consejo Asesor Indígena - } \\
\text { CAI, Consejo de Comunidades Indígenas } \\
\text { (CODECI), Comunidades Mapuche-Tehuelche } \\
\text { agrupados en la } 11 \text { de Octubre, en Pu Weche } \\
\text { Lafkenche, Comunidad Paicil Antrito, entre } \\
\text { otras. }\end{array}$ \\
\hline Regiones de Formosa: & $\begin{array}{l}\text { Comunidades Toba Nam Qom (lote 68), Pilagá } \\
\text { (Campo del Cielo y Kilómetro 30). }\end{array}$ \\
\hline Cordón verde de Buenos Aires: & $\begin{array}{l}\text { Asociación de Productores Parque Pereyra Iraola, } \\
\text { Asociación de Productores de Florencio Varela, } \\
\text { entre otros. }\end{array}$ \\
\hline Norte mendocino: & Unión de Trabajadores Rurales Sin Tierra - UST \\
\hline Este formoseño: & $\begin{array}{l}\text { Colonias agrupadas en asociaciones de ferias } \\
\text { francas y en el Movimiento Campesino de } \\
\text { Formosa-MOCAFOR }\end{array}$ \\
\hline Yungas salteñas: & $\begin{array}{l}\text { Comunidad Ava Guaraní de la Loma - Tabacal, } \\
\text { Comunidad Kolla-Guaraní Río Blanco Banda } \\
\text { Norte de Orán, Organización Zlaqatahyi (Unión } \\
\text { Wichí del Itiyuro), }\end{array}$ \\
\hline Impenetrable chaqueño: & Comunidades del pueblo Wichí del Impenetrable. \\
\hline Centro oeste chaqueño: & $\begin{array}{l}\text { Unión de Campesinos Poriajhú, Union } \\
\text { Campesina de Pampa del Indio, UNPEPROCH, } \\
\text { UNPEPROCE, APPCH, entre otras. }\end{array}$ \\
\hline Frente sojero / frontera agrícola del sureste salteño: & $\begin{array}{l}\text { Comunidad Wichí "Eben Ezer ("Reserva } \\
\text { Pizarro": lotes fiscales } 32 \text { y 33), Puesteros de las } \\
\text { Lajitas, entre otras. }\end{array}$ \\
\hline Quebrada de Humahuaca: Jujuy & $\begin{array}{l}\text { Comunidades del pueblo Kolla, Red Puna, entre } \\
\text { otras. }\end{array}$ \\
\hline
\end{tabular}

Fuente: elaboración propia a partir del banco de datos sobre conflictos por la tierra 1985-2010.

Las disputas por la tierra que parecían dar cuenta de todo el conjunto de conflictos frente al avance de las modalidades extractivas de producción primaria, fueron abriendo paso a otras demandas ${ }^{25}$ : a) Justicia ambiental; y b) Derechos territoriales y comunitarios.

Se trató de una ampliación de la semiótica y la programática política, a partir de la cual los conflictos por la tierra se articularon en el discurso ecológico y en la reivindicación territorial. La disputa por la tierra comenzó a presentarse combinada con exigencias de

${ }^{25}$ Ver "La ausencia campesina en la Argentina como producción científica y enfoque de intervención" (BARBETTA, DOMÏNGUEZ y SABATINO, op cit). 
reconocimiento étnico, o bien con reclamos y denuncias por el acceso y uso de los bienes comunes naturales: contra la contaminación por efecto de las fumigaciones con agroquímicos, por el acceso a vertientes y fuentes de agua dulce, por la preservación de bosques o montes nativos, por la disposición estacional de áreas de pastoreo, recolección o de pesca, etc. Innumerables acciones registran este tipo de articulaciones entre el derecho a la tierra, a la alimentación y al ambiente, apelando a múltiples interlocutores, sobre todo en ámbitos urbanos: como se observa en la consigna de la multisectorial contra la "ley Monsanto de semillas": "Quien controla la semillas, controla la alimentación”. O bien, como el caso de la "marcha" por las calles de Córdoba capital contra los desmontes, realizada por el MNCI bajo la consigna "Por un campo con campesinos y una Córdoba con bosques; por tierra y bosques en muchas manos y alimentos sanos para todos".

La imbricación entre conflictos por el control y uso del espacio sostenidos por poblaciones rurales y locales tenía como trasfondo un escenario de alianzas entre el activismo campesino e indígena con movimientos ambientalistas, asambleas de vecinos de pequeñas ciudades, organizaciones de desocupados urbanos, entre otros. A su vez, en simultáneo, otro tipo de poblaciones comenzaron a movilizarse ante los impactos negativos de la intensificación de la agricultura industrial que sobrevino con las innovaciones biotecnológicas. Es el caso de las pequeñas urbanizaciones o cordones periurbanos ligados o expuestos a los agroquímicos de los nuevos paquetes tecnológicos, en el marco del avance de la lógica de los agronegocios. También vale para las poblaciones urbanas cercanas a las áreas de explotación de la mega-minería.

\section{Mapas I: conflictos por tierra según departamento/municipio y casos de asesinatos de campesinos e indígenas según provincia, año 2010.}




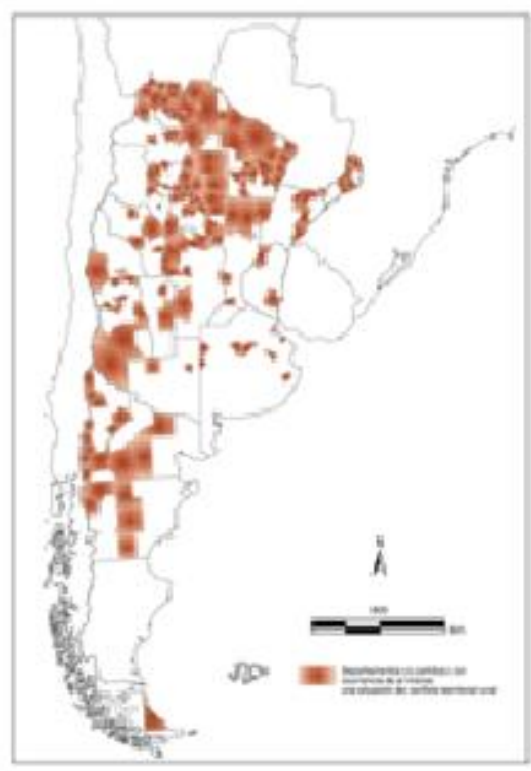

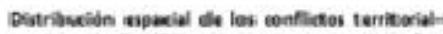

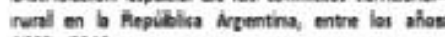
1583.2010

Fuente: Domilnquer, 2011.

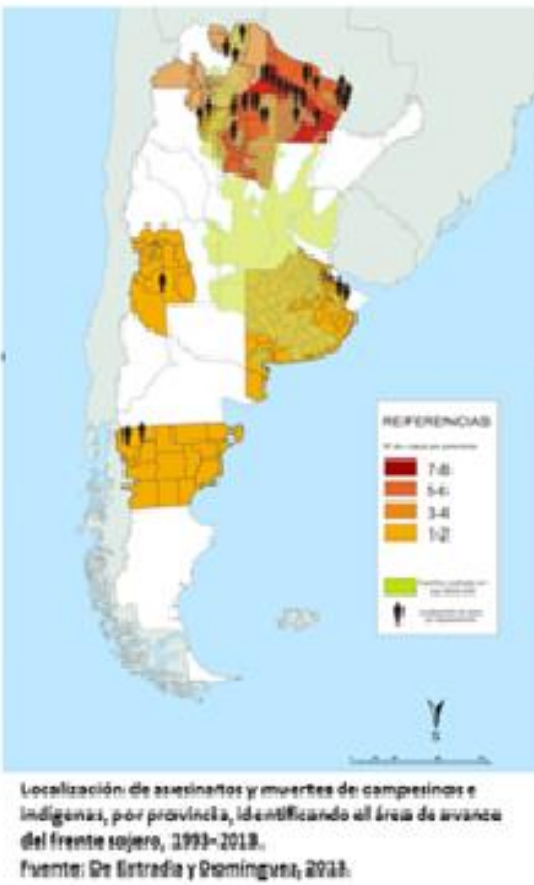

Fuente: Domínguez ${ }^{26}$, y De Estrada y Domínguez ${ }^{27}$.

\section{Territorialidades del campesinado y los pueblos originarios}

Parte de la reactualización del debate sobre la cuestión campesina ha puesto foco, además del permanente interés por la delimitación socio-económica del sujeto y su participación en procesos estructurales, en su activismo político, en los procesos de etno-génesis, en la producción de juridicidades y saberes subalternos, y en la relación con el Estado y las acciones de gobierno, en un periodo histórico signado por lo que algunos llaman nuevo “extractivismo" de las riquezas naturales de los pueblos $\left(\right.$ Zibechi $\left.^{28}\right)$, y otros inscriben en la "segunda ola de cercamientos" de los bienes comunes $\left(\right.$ Boyle $\left.^{29}\right)$.

Un conjunto de referentes académicos a nivel continental y global entienden que en escenarios paradójicos, de pobreza rural, cambio cultural y tecnológico, migración campo-ciudad, y afianzamiento del capital en todas las etapas de la producción

\footnotetext{
${ }^{26}$ DOMÏNGUEZ, op cit.

${ }^{27}$ DE ESTRADA, María y DOMÏNGUEZ, Diego. "Asesinatos y muertes de campesinos en la actualidad argentina: la violencia como dispositivo (des)territorializador". Revista Astrolabio. 2013. N ${ }^{\circ}$ 10. ISSN 1668-7515.

${ }^{28}$ ZIBECHI, Raul. El extractivismo como cultura. La Jornada de Mexico. 2016. Disponible en: http://www.jornada.unam.mx/2016/10/14/opinion/020a2pol. Acceso 04/02/2017.

${ }^{29}$ BOYLE, James. The second enclosure movement and the construction of the public domain. 2003. Disponible en: http://www.cooperationcommons.com/node/408. Acceso el 05/02/2017.
} 
agropecuaria, no obstante el campesinado vive tiempos de "clasificación" (Quijano ${ }^{30}$ ), "re ruralización" (Bengoa $\left.{ }^{31}\right)$, o de "recreación" $\left(\operatorname{Shanin}^{32}\right)$, que ha "resucitado" con vigor e imaginación (Bartra y Otero ${ }^{33}$ ). Los movimientos campesinos y por su parte los pueblos originarios, registran desde la década de 1980 en nuestros países, una intensa presencia en las arenas públicas, y además un desplazamiento de sus luchas por la tierra al reclamo territorial, como también lo viene reflejando la alianza global Vía Campesina en sus conferencias y documentos (https://viacampesina.org/es/index.php/nuestrasconferencias-mainmenu-28). Lo campesino se destaca al presente como dimensión política que persigue instituir la reconstrucción del vínculo directo de apropiación de las condiciones materiales y simbólicas de producción y reproducción, gestando así una propuesta territorial.

En referencia a las territorialidades campesinas existe una creciente bibliografía sobre el tema en Latinoamérica ${ }^{34}$ donde se retoman las propuestas teóricas que destacan la dimensión conflictiva de la gestación de territorios y se relacionan estas territorialidades con un modelo de producción de espacio "alternativo" o diferenciado del que produce el capital, como emblemáticamente lo ejemplifican las investigaciones sobre las Reservas Extractivistas y los asentamientos del Movimiento Sin Tierra en Brasil (Fernandes ${ }^{35}$; Porto Gonçalves ${ }^{36}$ ) o las Zonas de Reserva Campesina de Colombia (ZRC). Para las realidades de Argentina pueden recogerse definiciones como las que brinda el trabajo de

\footnotetext{
${ }^{30}$ QUIJANO, Aníbal. "Los movimientos campesinos contemporáneos en América Latina”. En Revista OSAL. Ed CLACSO. 2000.

${ }^{31}$ BENGOA, José. "Pueblos indígenas, Tierras y Territorios". En Eguren Fernando (editor): Reforma Agraria y Desarrollo Rural en la Región Andina. Lima: CEPES. 2006.

32 SHANIN, Teodor. "Lições camponesas". En E. Paulino y J. E. Fabrini (org.): Campesinato e territorio em disputa. São Paulo: Expressão Popular. 2008.

${ }^{33}$ BARTRA, Armando y OTERO, Gerardo. "Movimientos indígenas campesinos en México: la lucha por la tierra, la autonomía y la democracia”. En S. Moyo y P. Yeros (coord.): Recuperando la tierra. El resurgimiento de movimientos rurales en África, Asia y América Latina. Buenos Aires: CLACSO, Consejo Latinoamericano de Ciencias Sociales. 2008.

${ }^{34}$ Sobre este punto pueden consultarse un vasto conjunto de trabajos de los integrantes del GT-CLACSO "Desarrollo Rural" en la biblioteca virtual de CLACSO: http://biblioteca.clacso.edu.ar/. Otros autores latinoamericanos consultados en esta temática: Rosa De la Fuente Fernández; Luis Daniel Hocsman; Gabriela Torres-Mazuera; Carlos Vacaflores; Camilo Alejandro Bustos Avila; Ione Vieira dos Santos, Noemi Miyasaka Porro y Roberto Porro, Estevan Leopoldo de Freitas Coca, entre otros.

${ }^{35}$ FERNANDES, Bernardo Mançano. A formação do MST no Brasil. Petrópolis: Vozes, 2000.

${ }^{36}$ PORTO GONÇALVES, Carlos Walter. Geo-grafías. Movimientos Sociales, Nuevas Territorialidades y sustentabilidad. México. Siglo XXI. 2001.
} 
Monica Bendini y Norma Steimbreger ${ }^{37}$, donde la territorialidad campesina refiere a la persistencia -en situación de vulnerabilidad- de productores campesinos mediante “estrategias adaptativas y organizativas" en un escenario de expansión concentrada. En este trabajo, como en otros, la territorialidad campesina aparece asociada con la renovada vigencia de la cuestión agraria, que significa para el caso en estudio el aumento de unidades campesinas (crianceros patagónicos) dedicadas a la trashumancia ovina y caprina como movimiento espacial productivo de tipo pendular entre distintos pisos ecológicos para la invernada y veranada.

La territorialidad campesina e indígena se presenta como modo de organizar el espacio (conjunto de valores y acciones cotidianas), ya sean las formas de tenencia de la tierra, como las formas de gestión de la producción, es decir, ligada directamente con la reproducción material y simbólica de los sujetos.

Sin embargo, la dimensión política de la recreación campesina e indígena, permite hacer hincapié en los procesos de disputa en torno de la apropiación de la naturaleza y la producción de territorio. En este sentido, la ocupación de tierras $^{38}$ es un indicador de la vitalidad social y política del campesinado como productor de espacialidad. Sea como estrategia familiar o como accionar de las organizaciones campesinas, la ocupación de tierras se instala como camino alternativo al de la migración a la ciudad y a la proletarización, como un factor de producción y reproducción del campesinado $\left(\mathrm{Paz}^{39}\right.$; Barbetta, Domínguez y Sabatino ${ }^{40}$ ). Pero existen en Argentina otros indicadores de esta vitalidad del campesinado y los pueblos originarios.

\footnotetext{
${ }^{37}$ BENDINI, Mónica y STEIMBREGER, Norma (2013) "Territorialidad campesina en el sur de Argentina. Cambios productivos y laborales como formas de resistencia". En Revista Eutopia. Sept 2013. N 4. Pag 25-44.

${ }^{38}$ Cabe aclarar que no se usa esta noción en términos jurídicos, tampoco asociada a la categoría de "usurpación". Por el contrario, utilizamos la noción de ocupación de tierra como acción de territorializar la propia "intencionalidad", como capacidad de materializar la propia existencia campesina en un espacio determinado adquirido en forma reciente.

39 PAZ, Raúl. "¿Desaparición o permanencia de los campesinos ocupantes en el noroeste argentino? Evolución y crecimiento en la última década". En Canadian Journal of Latin American and Caribbean Studies, Canadá, 2006, Vol. 31, № 61.

${ }_{40}$ BARBETTA, Pablo, DOMINGUEZ, Diego y SABATINO, Pablo. "La ausencia campesina en la Argentina como producción científica y enfoque de intervención". En Revista Mundo Agrario - De Estudios Rurales, Buenos Aires, Centro de Historia Argentina y Americana (IdIHCS - UNLP CONICET), segundo semestre 2012, $\mathrm{N}^{\circ} 25$.
} 
Listamos a continuación algunas de las modalidades de territorialidad que reconocemos en la experiencia del campesinado y los pueblos originarios de Argentina a partir de su irrupción política:

- En la producción/procesamiento/comercialización: cooperativas de trabajo, producción agroecológica, agroindustrias locales, turismo rural, redes de comercio justo, "ferias francas" de alimentos locales, carnicerías cooperativas, ferias de intercambio de semillas, elaboración de maquinaria apropiada.

- En las modalidades comunitarias de acceso y tenencia de la tierra: "parcelas" o “campos comuneros", "asentamientos comunitarios", "reservas comunitarias".

- En la creación y gestión de políticas públicas: elaboración de la ley de la agricultura familiar (aprobada sin presupuesto), gestión directa de políticas de la SAF, participación en las decisiones de organismos públicos referidos a la atención de pueblos originarios (Instituto Nacional de Asuntos Indígenas y dependencias provinciales).

- En la formación y educación popular: escuelas y tecnicaturas en agroecología, “Universidad Campesina” (UNICAM), talleres de formación política.

Son experiencias llevadas a cabo por distintas organizaciones del campesinado y los pueblos originarios. En resumen apretado destacamos las articulaciones a escala regional o nacional, y expresiones locales de pueblos originarios: Movimiento Nacional Campesino Indígena (MNCI), Asamblea Campesina Indígena del Norte Argentino (ACINA), Frente Nacional Campesino (FNC), Consejo Asesor Indígena (CAI Mapuche), Qollamarka, Lhaka Honhat (multiétnica), entre otras de igual significancia, y agrupando a varias de estas instancias ante el Estado, el Consejo (asesor) de Agricultura Familiar, Campesina e Indígena ${ }^{41}$.

Estas experiencias caracterizan territorialidades diferenciadas de aquella territorialidad que impulsa el patrón capitalista de desarrollo agrario actual. Más aun, en general se definen a sí mismas como parte de una territorialidad que confronta con lo que

\footnotetext{
${ }^{41}$ Federación de Organizaciones Nucleadas de la Agricultura Familiar (FONAF), Asamblea Campesina Indígena del Norte Argentino (ACINA), Movimiento Nacional Campesino Indígena (MNCI), Frente Nacional Campesino (FNC), Grito de Alcorta, Movimiento Campesino de Liberación (MCL), Unión de Pescadores Artesanales (UAPA), Encuentro de Pueblos Originarios (ENOTPO), Organización Nacional de Pueblos Indígenas de Argentina (ONPIA), Asociación Mujeres Rurales (AMRAF), Frente Agrario Evita, Federación Agraria y Movimiento Agroecológico Latinoamericano (MAELA).
} 
denominamos "monopolización capitalista del territorio" (para profundizar el concepto citado puede leerse: Tomiasi Paulino y Aparecida de Almeida ${ }^{42}$, 2010). No obstante, son territorialidades que se producen a instancias de la territorialización de la lógica de los agronegocios, y no pueden pensarse escindidas de la reproducción social del espacio agrario por el capital. De un modo u otro, el denominador común a todas estas territorialidades es que se despliegan como propuesta de control y configuración de un espacio propio, indígena y/o campesino. Así comprendidas estas territorialidades, su definición se acerca a aquella elaborada por el geógrafo Marcelo Lopes Souza ${ }^{43}$ : los "territorios disidentes" (en resistencia y conflicto). Para este autor el carácter "disidente" de los territorios refiere, más que a espacios aislados culturalmente o económicamente autosuficientes, a aquellos espacios regidos por alguna forma de autogobierno o nivel de autogestión, libre de jerarquías, cuya soberanía reside en el propio grupo contra una legitimidad originada en fuentes externas o trascendentales de poder. Se trata no obstante de acciones de territorialización en general de escala local, y de corta duración, marcadas por la inestabilidad.

El carácter disidente llevado a la territorialidad campesina o indígena significaría su diferenciación frente a las territorialidades que tratan de hegemonizar la configuración de los mundos agrarios y rurales en la actualidad, reinscribiendo la problemática del acceso a la tierra en la defensa de un modo de vida, recuperando la figura del productor directo y la comunidad, y estableciendo el derecho a un tipo de configuración territorial singular frente a formas hegemónicas de producción del espacio social agrario/rural, a distancia de la integración nacional homogeneizante, del sistema jurídico formal y los encadenamientos agroindustriales (Barbetta, Domínguez y Sabatino ${ }^{44}$ ).

\section{Actualidad de la cuestión campesina e indígena en Argentina}

Como señalamos previamente, el escenario agrario de la cuestión campesina e indígena ha sido definido como modelo de agronegocios. La lógica del modelo se ha caracterizado

\footnotetext{
${ }^{42}$ TOMIASI Paulino, Eliane y APARECIDA de Almeida, Rosemeire. Terra e Territorio: a questao camponesa no capitalismo. Sao Paulo. Ed Expressao Popular. 2010.

${ }^{43}$ LOPES SOUZA, Marcelo. "Territorio da divergencia (e daconfusao)". En Marcos Aurelio Saquet y Eliseu Saveiro Sposito (org). Territorios e Territorialidades. Sao Paulo. Ed Expressao Popular. 2009. Pag. 57-72.

${ }^{44}$ BARBETTA, DOMÍNGUEZ y SABATINO, op cit.
} 
por la predominancia de empresas transnacionales, fuerte presencia del capital financiero y la producción de commodities, y a su vez se ha vehiculizado con un redoble de los frentes agropecuarios y la intensificación del paradigma de la agricultura industrial. Como tal se consolidó en la década de 1990. Recordemos dos hechos paradigmáticos: el decreto presidencial (DNU) de desregulación que eliminó los organismos estatales para el agro (1992), y la aprobación de la soja resistente al glifosato (1996) que haría pivotear al sector hacia la agricultura transgénica. Todos estos rasgos perduraron y se profundizaron en la llamada "década ganada" o los sucesivos gobiernos kirchneristas.

En términos muy amplios se podrían marcar dos cuestiones respecto del contexto agrario de la cuestión campesina e indígena en la Argentina actual. En el plano de las continuidades desde la década de 1990 hasta la actualidad se ha mantenido la gramática de poder (como solía decir Norma Giarracca) que estructura el sistema agro-industrialalimentario, que algunos engloban en el esquema extractivista bajo el "consenso de los commodities". En el plano de las rupturas, podría señalarse que el periodo anterior estuvo signado por el intento estatal de instalar niveles de sustentabilidad social y ambiental (leyes de bosques, glaciares, agricultura familiar, extranjerización de tierras), y redistribución de la riqueza generada por el sector, sobre todo de la renta agraria (retenciones mediante, más allá de reintegros, subsidios, compensaciones, etc, hacia subsectores del agro). Más allá de las consecuencias coyunturales que traigan las inundaciones para la esta campaña, con la eliminación parcial de retenciones se instala así un nuevo escenario en el cual se recuperan niveles de rentabilidad para zonas extrapampeanas que habían quedado otrora rezagadas a partir de la combinación de aumento de retenciones y baja en los precios de los commodities. Se tratan de condiciones generales que habrá que revisar frente a los efectos de escenarios específicos que pudieran relativizarlas al tener en cuenta aumento de los insumos importados, o de los combustibles, nuevas bajas en los precios de los granos, etc.

De todo ello se infiere que estamos frente a un escenario posible de intensificación en la presión sobre los recursos naturales, básicamente tierra, con el correlato observable en el 
periodo anterior, de desmontes ${ }^{45}$, contaminación por agroquímicos, y conflictividad territorial con dosis trágicas y crueles de violencia.

Actualmente, las acciones de Estado del gobierno de Cambiemos (Mauricio Macri), entendemos operan para el escenario agrario general en línea con el fortalecimiento de la lógica de los agronegocios y de la reconcentración económica. Indicadores en el sentido de las rupturas y continuidades con el proceso anterior, van desde la transferencia de ingresos que ha significado la porción que el Estado ya no retiene por la exportaciones primarias, más la devaluación del peso, la permanencia de funcionarios públicos que ha sido notoria en el caso de personas vinculadas a empresas de biotecnología y agronegocios en general, la rápida aprobación de nuevas semillas transgénicas, impulso de una ley se semillas que las retira del dominio público y las mercantiliza definitivamente. Estas acciones ya están marcando procesos que, si bien son incipientes en su magnitud, dejan ya huellas observables para las agriculturas familiares, campesinas y los pueblos originarios.

A seguir señalamos tres dimensiones que afectan a estos sujetos en términos de continuidades y rupturas: acceso al Estado, mediación institucional, y conflictividad rural.

\section{Acceso al Estado}

Desde su creación la Secretaria de Agricultura Familiar (SAF) ${ }^{46}$ había significado un espacio problemático para las organizaciones campesinas. Según lo enunciaban las dirigencias campesinas este vínculo implicaba un desafío: como mantener la distancia necesaria con el Estado para hacer valer los propios reclamos y derechos, a la vez que aprovechar una oportunidad de participar directamente en la gestación y conducción de políticas para el sector. Teniendo en cuenta que este organismo formaba parte de un ministerio volcado mayormente a favor de los intereses de los actores del agronegocio.

\footnotetext{
${ }^{45}$ Recordemos que en el periodo anterior se había pasado de un desmonte de 644 hectáreas por día en 2012 (cuando se pone en marcha ley luego de OTBN en cada provincia), a un desmonte de 391 hectáreas por día en 2015.

46 En octubre de 2008 (luego del conflicto llamado "campo-gobierno"), se crea la Subsecretaria de Desarrollo Rural y Agricultura Familiar (reuniendo varios programas que atendían a productores familiares, campesinos, comunidades indígenas, etc.). En 2014 estas funciones pasan a la órbita de un organismo de mayor rango creándose la Secretaria de Agricultura Familiar (SAF), a cargo de Emilio Pérsico.
} 
Independientemente de esta ecuación era posible observar la importancia que tenía para el sector contar con una instancia propia al interior del aparato estatal. Este escenario anterior al nuevo gobierno (2016) ha sido cambiado, y en su lugar al 2016 puede observarse es una fractura en el acceso al Estado por parte de los sectores que este organismo debiera atender: falta presupuesto, sin ejecución, despidos de técnicos, sin secretario ${ }^{47}$ y desmantelamiento de áreas sensibles.

Con el cambio de gobierno lo que al momento se observa es la continuidad en la falta de presupuesto para la $\mathrm{SAF}^{48}$, estamos frente a un organismo paralizado, que no ejecuta, más allá de cualquier definición técnica de aquello que se entienda por intervención estatal hacia las agriculturas familias, campesinas y los pueblos originarios.

Por otra parte, según denuncia el gremio ATE, durante el año de 2016, contabilizaron 250 técnicos despedidos, en muchos casos incluso en un marco de discriminación política y estigmatización social (llamados "ñoquis" o "militantes"). También se denuncia que por detrás de estos despidos existe una desarticulación de áreas de intervención estatal estratégicas para el sector. En algunas provincias han sido desactivados equipos de trabajo ligados a la problemática de la tierra, cuestión de lo más sensible para campesinos y pueblos originarios. Pero hay otros ejemplos. Según lo denuncia el Movimiento Nacional Campesino Indígena (MNCI) se ha eliminado la Subsecretaría de Fortalecimiento Institucional "que garantizaba la participación de todas las organizaciones campesinas y agricultores familiares en la implementación de las distintas políticas del área" (ver nota diario Página 12: http://www.pagina12.com.ar/diario/economia/2-292328-2016-0212.html).

Un caso sintomático de esta fractura es lo ocurrido en la delegación de la SAF de Santiago del Estero. Allí las organizaciones campesinas denuncian que a cargo del organismo han ubicado a un empresario del agro (Carlos Cejas Lescano) al que se responsabiliza por torturas y conducir bandas armadas para el desalojo de familias campesinas. Como

\footnotetext{
${ }^{47}$ Con el nuevo gobierno asumió el cargo el ingeniero Oscar Alloatti, a quien se le pidió la renuncia a menos de un año de trabajo, en octubre de 2016. La Secretaria de Agricultura Familiar está provisoriamente a cargo del jefe de gabinete del ministerio.

${ }^{48}$ Las organizaciones campesinas exigen en este sentido que se reglamente la ley de "reparación histórica de la agricultura familiar", $\mathrm{n}^{\circ} 27.118$.
} 
respuesta las organizaciones han ocupado de forma pacífica las oficinas provinciales de la SAF el 19 de abril exigiendo la renuncia del delegado.

Luego de la renuncia del Secretario (en octubre de 2016), el organismo quedo prácticamente paralizado, en un tiempo de espera que el ministro de agroindustria denominó como de "reestructuración" (ver diario La Nación: http://www.lanacion.com.ar/1946338-primera-baja-en-agroindustria-en-medio-derestricciones-presupuestarias-se-fue-alloatti).

\section{Mediación institucional}

Producto de los reclamos de las organizaciones campesinas y de la Federación Agraria la Secretaria de Agricultura y luego Ministerio habían ido abriendo instancias de representación sectorial ante el Estado. El Foro de la Agricultura Familiar (2006) era una de estas instancias. Creado en el marco de las reuniones especiales para la agricultura familiar del Mercosur (REAF), donde participaban organismos estatales y organizaciones sectoriales. Muchas organizaciones campesinas de Argentina vieron allí estructuras paraestatales de representación y mantuvieron sus propios canales de negociación con los funcionarios del Estado. Los pueblos originarios por su parte mantuvieron distancia, relegando su presencia a la participación individual de dirigentes o referentes de comunidades. Más tarde (2014), desde la SAF se crearon instancias de interlocución directa de las organizaciones con el Estado, y de mediación para la resolución de conflictos de tierra (reuniendo a empresas del agro y organizaciones campesinas e indígenas), habida cuenta de la creciente violencia que en las disputas comenzó a instalarse (recordemos las decenas de asesinatos en conflictos de este tipo ${ }^{49}$ ): destacamos por ejemplo, a nivel nacional el Consejo de la Agricultura Familiar y Campesina, y el espacio interinstitucional para la resolución de conflictos de tierra llamada Mesa Nacional de Dialogo para la Agricultura Sustentable, con actuación también según cada provincia.

Con respecto a estas dos instancias, según las nuevas autoridades de la SAF, se habló de su continuidad, inclusive en lo que va del 2016 hubo algunas reuniones de la Mesa de

\footnotetext{
${ }^{49}$ Ver https://observatorioviolenciarural.wordpress.com/
} 
Diálogo. Sin embargo, las organizaciones del sector entienden que no está clara esta intención dejando entrever la fragilidad de la permanencia de estas instancias, que tienen como mediador e interlocutor al Estado.

\section{Conflictividad rural}

Desde el regreso de la democracia en la década de 1980 hasta la actualidad hay dos procesos que atraviesan a las poblaciones rurales: por un lado, la presión empresarial y estatal sobre sus tierras y territorios, y por otro lado, un creciente activismo político visible en la conformación de organizaciones en diferentes escalas, y en el fortalecimiento de comunidades de base territorial. En esta clave de análisis puede observarse la emergencia política de los pueblos originarios y del campesinado, así como la recreación de agrupaciones que reivindican a la persistencia de las agriculturas familiares capitalizadas. A su vez pueden observarse los avances de los frentes agropecuarios, con sus consecuencias en términos de degradación de los ecosistemas y agroecosistemas locales, y de despojo de las poblaciones nativas.

Como saldo de todo ello, ya desde finales de los años de 1980 se registra una creciente conflictualidad que tiene como centro el control de los bienes comunes de la naturaleza, fundamentalmente la tierra, pero también el bosque autóctono, el acceso al agua, a las semillas, y a un ambiente sano. Durante el año de 2016 esta conflictualidad tuvo su expresión en la escala local, observable en el marco de cada conflicto por tierra, sin embargo también se la registró en la escala provincial, nacional y global.

En la escala nacional, uno de los puntos más críticos fue alrededor de la movilización que realizó el Consejo de Agricultura Familiar, Campesina e Indígena, en octubre, a las puertas del Ministerio de Agroindustria en la Ciudad de Buenos Aires. Allí se logró aglutinar una serie de reclamos ante el Estado. En esta oportunidad se cuestionó la "grave situación del sector" y el "vaciamiento de las instituciones específicas", focalizando en cinco ejes: a) la falta de reglamentación de la ley para la agricultura familiar; b) el rechazo al proyecto de ley de semillas promovido por las empresas transnacionales; c) el rechazo al proyecto de ley sobre fitosanitarios; d) la denuncia al recorte presupuestario en el Instituto Nacional de Tecnología Agropecuaria (INTA) y en la SAF; e) contra el despido 
de trabajadores del Ministerio de Agroindustria. Por su parte la escala local de esta conflictualidad viene siendo estudiada por múltiples investigadores y equipos, y desde distintos enfoques analíticos. En términos de los análisis cuantitativos destacamos el trabajo de la Subsecretaria de Agricultura Familiar comprendiendo problemas de tierra del $2011^{50}$, del observatorio de la Red Agroforestal Chaco (REDAF) ${ }^{51}$, y el nuestro propio $^{52}$.

A continuación analizamos un conjunto de conflictos y acciones del campesinado, los pueblos originarios y la agricultura familiar, emergentes a partir de enero 2016 en medios de comunicación nacionales o comunicados de las principales organizaciones que agrupan a estos sujetos (ver cuadro acciones/conflictos). En el actual escenario observamos que los conflictos por tierra (y territorio) campesino o indígena, mantienen los mismos patrones que caracterizaron la conflictualidad de todo el periodo anterior.

Contra los desalojos:

Los conflictos que protagonizan las poblaciones rurales desde inicio del 2016 se refieren a denuncias y acciones ante intentos de desalojo o usurpación de tierras. Se trata de familias o comunidades que resisten la apropiación de sus tierras que se opera por la vía de desalojos judiciales o bien bajo la modalidad de bandas armadas que ejecutan un repertorio amplio de acciones de violencia. Es común vincular la realidad de los desalojos con las formas precarias de tenencia de la tierra o situaciones problemáticas de tierra, solucionables en base a políticas de regularización. Si bien esto es cierto, habría que agregar que los intentos de desalojo se inscriben en el desconocimiento o desprecio por las modalidades alternativas de organizar los sistemas agroalimentarios, por la ausencia de políticas de tierra que reconozcan la tenencia comunitaria para comunidades campesinas, y además que avancen más allá de la tenencia y aborden el problema del acceso a la tierra para nuevas familias, jóvenes campesinos, o cubrir demandas originadas en la reorientación productiva de los campesinos.

\footnotetext{
${ }^{50}$ Este organismo, dependiente en aquel momento de la Secretaria de Desarrollo Rural y Agricultura Familiar, publicó en 2013 un documento conteniendo un estudio de problemas de tierra sobre 857 situaciones, sobre un total de 9.293.233 de hectáreas, implicando 63.843 familias.

${ }^{51}$ http://redaf.org.ar/observatorio/

52 Ver artículo "La territorialización de la lucha por la tierra en la Argentina del bicentenario", en Revista Antropología y Derecho, ISSN 1668-7639. ed CEDEAD. diciembre 2010. Posadas - Misiones
} 
Antagonismo con los agronegocios:

Las familias, comunidades y organizaciones implicadas en conflictos de tierra denuncian como responsables de los intentos de desalojo vía legal y directa a los sectores más dinámicos del agro. Por un lado se trata de empresas productoras de commodities, como soja. También se encuentran entre las empresas implicadas en los conflictos aquellas referidas a la producción y procesamiento agroindustrial de alimentos o a la construcción de infraestructura energética. Es decir, no estamos frente a sectores residuales de economías locales tradicionales, marginales al proceso de desarrollo, como se los presenta desde medios de comunicación que tratan las noticias o desde voceros de los agronegocios (por ejemplo, ver entrevista a Hector Huergo: http://revistacrisis.com.ar/notas/el-tecnocrata-mesianico0\#sthash.Qbdzq8VU.dpuf). Esta dimensión de los conflictos puede observarse también en la composición de las entidades que participan de las mesas de diálogo para conflictos de tierra ${ }^{53}$ en representación de las "cámaras de agronegocios".

\section{Contaminación del territorio:}

Los conflictos por la tierra han sido analizados como parte de una disputa mayor por el territorio, sea porque es un reclamo de los mismos protagonistas, sea porque la apropiación o despojo de la tierra viene acompañada de luchas por el acceso al agua, uso de los bosques, y otros procesos de arrinconamiento de las poblaciones locales tales como la contaminación humana, animal y vegetal. Desde que avanzaron los nuevos paquetes tecnológicos de la agricultura transgénica e industrial en general, se ha intensificado el uso de agroquímicos, fundamentalmente el glifosato como base de los "coctel" que se aplican. Esto en un contexto de avance de la frontera agraria sobre zonas rurales pobladas, sobre todo en regiones extrapampeanas. De modo que han proliferado los casos de contaminación por el modelo de agricultura industrial (no estaríamos frente a meros “accidentes" reiterados), a los cuales deben sumarse aquellos casos de contaminación

\footnotetext{
${ }^{53}$ Se trata de la Mesa Nacional de Diálogo para la Agricultura Sustentable, convocado por la Secretaria de Agricultura Familiar, que mantiene reuniones periódicas en distintas provincias del país, tratando los conflictos de tierra como problemática general, y casos en particular con ánimo de resolverlos en base a nuevos consensos. En sus distintas versiones esta Mesa de Diálogo cuenta con la participación de distintas organizaciones campesinas e indígenas, de Federación Agraria, sectores de la Iglesia como la Pastoral Social, así como representantes del agro-empresariado por ejemplo la Asociación de Consorcios Regionales de Experimentación Agrícola (AACREA) o la Asociación Argentina de Productores en Siembra Directa (Aapresid), la Asociación de Semilleros Argentinos (ASA), entre otros sectores, como las ONGs de desarrollo rural.
} 
originados por mega-emprendimientos u obras de infraestructura. En tal sentido, los nuevos conflictos también presentan este perfil ligado a la distribución del daño ambiental. Durante este año tuvo media sanción legislativa en provincia de Buenos Aires una ley que reduciría a diez metros la distancia para la fumigación con agroquímicos, incluidos los cocteles de herbicidas como el glifosato y el 2.4D. Frente a esta medida hubo un rechazo coordinado entre organizaciones de productores familiares, campesinos, ambientalistas, y profesionales de la salud agrupados en la Red de Médicos de Pueblos Fumigados (http://reduas.com.ar/ley-procancer-en-provincia-de-buenos-aires/).

Judicialización de la resistencia:

Característica de la conflictividad por la tierra en décadas anteriores habían sido las denuncias penales contra integrantes de organizaciones campesinas e indígenas, o de integrantes de las familias que decidían resistir los desalojos, acusados de asociación ilícita o de usurpación, resistencia a la autoridad, etc. Entre los nuevos conflictos cabe mencionar en este sentido el caso de un fallo del supremo tribunal de justicia de Chaco para llevar a juicio oral una familia indígena (y una periodista) por resistencia "armada" frente a un intento de desalojo judicial, a pesar de otras actuaciones estatales que bregaban por el cumplimiento de los derechos indígenas (particularmente la moratoria contra desalojo de población indígena).

Control de las semillas:

Desde décadas anteriores se arrastra un conflicto en torno a los derechos de propiedad sobre las semillas, básicamente a partir de la difusión de los organismos genéticamente modificados (OGM) en la agricultura. El caso paradigmático es el de los intentos de la empresa Monsanto para el reconocimiento de patentes y cobro de regalías sobre las distintas semillas transgénicas de soja. Esto viene siendo denunciado por las organizaciones campesinas, y también ha sido denunciado en la justicia por la Federación Agraria Argentina que se erige como representante de los intereses de los agricultores familiares más capitalizados, implicados directamente en la producción de commodities genéticamente modificados (soja, maíz, etc). Durante este año avanzaron en comisiones legislativas diversos proyectos de ley sobre semillas, que modificarían la legislación actual que reconoce el derecho del productor de reproducir su semilla, el uso propio. El gobierno impulso un proyecto que llevaría la balanza hacia el derecho de patentamiento 
sobre las semillas, acotando el uso propio a situaciones excepcionales y borrando así cualquier elemento que refiera a carácter "comunal" de este bien (ver diario La Nación: http://www.lanacion.com.ar/1946265-que-dice-el-proyecto-de-ley-de-semillas-que-elgobierno-enviara-al-congreso). Como no hubo definiciones este año, el gobierno se prepara para retomar la iniciativa en 2017, como lo hacen también las organizaciones de la agricultura familiar que tienen su propio proyecto de ley, o quienes desde el campesinado y el ambientalismo coordinan acciones de resistencia a la que llaman "ley Monsanto". En el primer año del nuevo gobierno, y a 20 años de la aprobación de la soja transgénica (soja RR de Monsanto, resistente a herbicidas en base a glifosato), se aprobó el evento número 36. Se trata de un maíz transgénico presentado por Pioneer (Dupont), resistente a diversas plagas y herbicidas (ver nota Infocampo: http://www.infocampo.com.ar/aprueban-un-nuevo-maiz-transgenico/). Esto marca la continuidad de las políticas de Estado con respecto a la biotecnología aplicada al agro, que es transversal a los distintos gobiernos.

\section{Violencia rural:}

La presencia de situaciones de violencia en los casos de los conflictos emergentes van del asesinato, los heridos de bala, las golpizas y torturas, a la quema de viviendas, destrucción de cultivos o matanza de animales. Los responsables varían entre las fuerzas policiales de provincia a grupos armados contratados. La violencia rural durante este año pivoteo entre el intento de desarticulación de la resistencia campesina ante desalojos, como en los casos de Mendoza (empresa Argenceres y la UST, en Jocolí) y Santiago del Estero (empresa Manaos y MOCASE-VC, en Bajo Hondo), hasta la búsqueda de revancha o persecución sufrida por quienes participan de organizaciones campesinas locales en la gestión estatal (municipal $^{54}$, como en el caso del asesinato de la joven campesina de Estación Morillo, en Salta.

Reclamo al Estado:

\footnotetext{
${ }^{54}$ La víctima era sobrina de una importante dirigente campesina participante de la experiencia de control del aparato estatal local en alianza con el Frente para la Victoria. Esta experiencia de poder local campesino logro posicionar como intendenta a Marcela Carabajal (Partido de la Victoria de Salta), sucediendo al denunciado por desmanejo de fondos públicos Atta Gerala (que nuevamente es intendente) y sospechoso de estar detrás del asesinato de la joven y de otro activista local (pariente también de la misma dirigente).
} 
Conjuntamente con las acciones de resistencia directa en los conflictos de tierra las organizaciones campesinas e indígenas han impulsado acciones hacia el Estado, reclamando por política públicas, presentando leyes, dando batalla legal, etc. Las leyes contra desalojos para el campesinado y los pueblos originarios, inclusive la ley de la agricultura familiar son ejemplos, más allá de que su incumplimiento efectivo ha primado sobre su capacidad de realizar derechos. La creación de la Secretaria de Agricultura Familiar también ha sido un ejemplo, en tanto herramienta de fortalecimiento económico y político del sector. En el escenario actual, las organizaciones sobre todo campesinas reclaman la falta de presupuesto para el funcionamiento del organismo mencionado, el cierre de las instancias de diálogo Estado-sector, el desmantelamiento de áreas estatales estratégicas en materia de problemas de tierra y la persecución ideológica de técnicos. Estos reclamos tienen puntos críticos en casos como el de Santiago del Estero, donde las organizaciones campesinas ocuparon las oficinas de la Secretaria de Agricultura Familiar, argumentando que el actual "Delegado" a cargo es un empresario productor de soja responsable de desalojos violentos contra familias campesinas. En octubre se realizó una importante movilización del sector frente al Ministerio de Agroindustria, denunciando entre otras cuestiones el vaciamiento de las políticas referidas a estas poblaciones rurales y modalidades de producción.

\section{Cuadro II: Acciones y Conflictos llevados a cabo por organizaciones campesinas,} indígenas y de la agricultura familiar, durante el año de 2016:

\begin{tabular}{|c|c|c|c|}
\hline Acción/Conflicto & Lugar & $\begin{array}{l}\text { Fecha } \\
(\mathbf{m m})\end{array}$ & Resumen \\
\hline $\begin{array}{l}\text { Conflicto entre } \\
\text { comunidad Pilagá y } \\
\text { empresa Techint por } \\
\text { gasoducto }\end{array}$ & $\begin{array}{l}\text { Pengole } \\
\text { Las } \\
\text { Lomitas } \\
\text { Formosa }\end{array}$ & 01 & $\begin{array}{l}\text { Comunidades Pilagá ( } 300 \text { familias) denuncian a Techint por } \\
\text { contaminación, y no cumplir con los derechos indígenas } \\
\text { (consulta y pago de canon), en la construcción de un gasoducto } \\
\text { que atraviesa sus territorios. }\end{array}$ \\
\hline $\begin{array}{l}\text { Conflicto } \text { de } \\
\text { entre tierras } \\
\text { campesinas } \\
\text { empresario }\end{array}$ & $\begin{array}{c}\text { Simbol } \\
\text { Bajo } \\
\text { y Lote } 39 \\
\text { Añatuya } \\
\text { Santiago } \\
\text { del Estero }\end{array}$ & 01 & $\begin{array}{l}\text { El MOCASE-VC denuncia atropellos al derecho posesorio de } \\
50 \text { familias campesinas y violencia directa, por parte del } \\
\text { empresario Domingo Tonani. Se trata de dos comunidades que } \\
\text { defienden sus tierras frente a las acciones de amedrentamiento } \\
\text { y desalojo. }\end{array}$ \\
\hline $\begin{array}{l}\text { Denuncia retención } \\
\text { ilegal sobre semillas }\end{array}$ & $\begin{array}{l}\text { Buenos } \\
\text { Aires } \\
\text { (CABA) }\end{array}$ & 02 & $\begin{array}{l}\text { La FAA amplía la denuncia contra Monsanto por el cobro de } \\
\text { regalías sobre el grano de soja (biotecnología intacta). } \\
\text { Defienden el uso propio de la semilla. }\end{array}$ \\
\hline $\begin{array}{l}\text { Conflicto de tierra entre } \\
\text { campesinos }\end{array}$ & $\begin{array}{c}\text { Bajo } \\
\text { Hondo } \\
\text { Santiago } \\
\text { del Estero }\end{array}$ & 02 & $\begin{array}{l}\text { MOCASE-VC denuncia que un empresario vinculado a } \\
\text { bebidas MANAOS (Orlando Canido) pretende desalojar } \\
\text { campesinos y ha desmontado más de } 500 \text { has para sembrar } \\
\text { soja, con apoyo de bandas armadas, en una zona habitada por } \\
60 \text { familias (comunidad Guaycurú). }\end{array}$ \\
\hline
\end{tabular}




\begin{tabular}{|c|c|c|c|}
\hline $\begin{array}{l}\text { Campesino baleado en } \\
\text { conflicto de tierra }\end{array}$ & $\begin{array}{c}\text { Jocolí } \\
\text { Mendoza }\end{array}$ & 02 & $\begin{array}{l}\text { La UST denuncia la detención de campesinos y la herida de } \\
\text { bala que sufrió Pablo Sarmiento, por la policía provincial } \\
\text { cuando la familia Sarmiento intentaba defender sus tierras ante } \\
\text { el avance de la empresa española Argenceres - Elaia SA. }\end{array}$ \\
\hline $\begin{array}{ll}\text { Conflicto } & \text { de tierras } \\
\text { entre } & \text { comunidad } \\
\text { campesina } & \text { Estado }\end{array}$ & $\begin{array}{l}\text { Esperanza } \\
\text { Misiones }\end{array}$ & 03 & $\begin{array}{l}\text { La comunidad campesina ( } 37 \text { familias del MNCI) del paraje } \\
\text { Sarandí } 2 \text { de febrero, municipio de Esperanza, denuncia el } \\
\text { tercer intento de desalojo que sufren, con la destrucción de sus } \\
\text { viviendas y cultivos, en operativos policiales con orden } \\
\text { judicial. }\end{array}$ \\
\hline $\begin{array}{l}\text { Denuncia por asesinato } \\
\text { de joven campesina }\end{array}$ & $\begin{array}{l}\text { Estación } \\
\text { Morillo } \\
\text { Salta }\end{array}$ & 03 & $\begin{array}{l}\text { Encuentran asesinada a Claudia Marisol Campos, sobrina de } \\
\text { Lucia Ruiz, importante dirigente campesina de la zona. } \\
\text { Familiares señalan razones políticas y al intendente como } \\
\text { responsable (Atta Gerala). }\end{array}$ \\
\hline $\begin{array}{l}\text { Familias campesinas se } \\
\text { reorganizan para } \\
\text { recuperar su territorio }\end{array}$ & $\begin{array}{l}\text { Piruaj Bajo } \\
\text { Copo } \\
\text { Santiago } \\
\text { del Estero }\end{array}$ & 04 & $\begin{array}{l}\text { Alrededor de } 80 \text { familias del paraje Piruaj Bajo reanudaron sus } \\
\text { acciones para recuperar las tierras de las que vienen siendo } \\
\text { desalojados por una empresa Sacha Rupaska SA y un } \\
\text { empresario tucumano (Cesar Pablo Esteban Bellati). Las } \\
\text { familias reclaman que se cumplan sus derechos sobre un total } \\
\text { de } 17.800 \text { hectáreas. }\end{array}$ \\
\hline $\begin{array}{l}\text { Reclamo contra la } \\
\text { violencia y usurpación } \\
\text { territorial }\end{array}$ & $\begin{array}{l}\text { Corral } \\
\text { Blanco } \\
\text { y Aguas } \\
\text { Calientes } \\
\text { Catamarca }\end{array}$ & 04 & $\begin{array}{l}\text { Comunidades del pueblo Diaguita denuncian públicamente y } \\
\text { ante autoridades las acciones violentas y los intentos de } \\
\text { usurpación que sufren. Se declaran en estado de alerta y exigen } \\
\text { a las autoridades que se garanticen sus derechos ancestrales. }\end{array}$ \\
\hline $\begin{array}{l}\text { Manifestación contra } \\
\text { desarticulación de las } \\
\text { políticas hacia la AF }\end{array}$ & $\begin{array}{l}\text { Buenos } \\
\text { Aires } \\
\text { (CABA) }\end{array}$ & 04 & $\begin{array}{l}\text { El MNCI realizó un reclamo frente a la sede del Ministerio de } \\
\text { Agroindustria. Ante las exigencias las autoridades se } \\
\text { comprometieron a reabrir el Consejo de la Agricultura } \\
\text { Familiar. }\end{array}$ \\
\hline $\begin{array}{l}\text { Manifestación } \quad \text { y } \\
\text { ocupación de } \\
\text { organismos públicos }\end{array}$ & $\begin{array}{l}\text { Santiago } \\
\text { del Estero } \\
\quad \text { (cap) }\end{array}$ & 04 & $\begin{array}{l}\text { Las distintas expresiones del MOCASE y otras organizaciones } \\
\text { (ATE, CTEP, etc) se manifestaron y ocuparon la oficina de la } \\
\text { Secretaria de la Agricultura Familiar SE denunciando a su } \\
\text { delegado (Carlos Cejas Lescano) por estar involucrado en } \\
\text { desalojo de campesinos, ejercer la violencia y despedir } \\
\text { técnicos. }\end{array}$ \\
\hline $\begin{array}{l}\text { Escrache y reuniones } \\
\text { con representantes y } \\
\text { funcionarios }\end{array}$ & $\begin{array}{l}\text { Mendoza } \\
\text { (cap) }\end{array}$ & 04 & $\begin{array}{l}\text { La UST se movilizó en la capital provincial haciendo un } \\
\text { escrache a la Secretaria de AF y al poder judicial, y } \\
\text { reuniéndose con diputados, senadores, y funcionarios del } \\
\text { gobierno provincial. Se reclamó: regularización tierras, } \\
\text { mensuras comunitarias, régimen alternancia campesina, etc. }\end{array}$ \\
\hline $\begin{array}{l}\text { Juicio contra familia } \\
\text { Qom por resistir } \\
\text { desalojo }\end{array}$ & $\begin{array}{l}\text { Pampa } \\
\text { Chica } \\
\text { Pampa del } \\
\text { Indio } \\
\text { Chaco }\end{array}$ & 04 & $\begin{array}{l}\text { El Supremo Tribunal de Justicia de Chaco confirmó la } \\
\text { realización del juicio oral contra familia Qom Adriani-Berdún } \\
\text { y a una periodista por resistencia "armada" al desalojo de sus } \\
\text { tierras en la zona rural del municipio de Pampa del Indio. }\end{array}$ \\
\hline $\begin{array}{l}\text { Comunidades } \\
\text { indígenas se oponen a } \\
\text { la minería a cielo } \\
\text { abierto }\end{array}$ & $\begin{array}{l}\text { La Puna } \\
\text { Jujuy }\end{array}$ & 05 & $\begin{array}{l}\text { Pueblos originarios de Cochinoca, Yavi, Rinconada, Santa } \\
\text { Catalina y Atacama, expresaron su rechazo de la minería a } \\
\text { gran escala y a cielo abierto por sus consecuencias negativas } \\
\text { sobre el ambiente y la sociedad. Se oponen particularmente a } \\
\text { la cesión de tierras ( } 90 \text { mil hectáreas) a la empresa canadiense } \\
\text { Dajin Resource. }\end{array}$ \\
\hline $\begin{array}{l}\text { Familias campesinas y } \\
\text { la FAA denuncian } \\
\text { intentos de desalojo } \\
\text { por parte de una } \\
\text { empresa }\end{array}$ & $\begin{array}{l}\text { Invernada } \\
\text { Norte y } \\
\text { Casti } \\
\text { Corral } \\
\text { Figueroa } \\
\text { Santiago } \\
\text { del Estero }\end{array}$ & 06 & $\begin{array}{l}29 \text { familias campesinas con apoyo de la Federación Agraria } \\
\text { denuncian las amenazas y quemas de casas y cercos que } \\
\text { realiza una empresa que pretende apropiarse de } 950 \text { has. }\end{array}$ \\
\hline
\end{tabular}




\begin{tabular}{|c|c|c|c|}
\hline $\begin{array}{l}\text { Confrontación entre } \\
\text { grupos mapuches y el } \\
\text { empresario Joe Lewis }\end{array}$ & $\begin{array}{l}\text { El Bolsón } \\
\text { Río Negro }\end{array}$ & 06 & $\begin{array}{l}\text { La agrupación Resistencia Ancestral Mapuche destruye } \\
\text { retroexcavadoras del magnate inglés, que realizan obras para } \\
\text { una central hidroeléctrica. Denuncian también la apropiación } \\
\text { de tierras mapuches. }\end{array}$ \\
\hline $\begin{array}{l}\text { Guaraníes denuncian } \\
\text { atentado y amenazas } \\
\text { por oponerse a un } \\
\text { emprendimiento } \\
\text { turístico }\end{array}$ & $\begin{array}{l}\text { Jahaveré } \\
\text { Esteros del } \\
\text { Iberá } \\
\text { Corrientes }\end{array}$ & 08 & $\begin{array}{l}\text { Familia guaraní de Jahaveré y la Comunidad pobladores de } \\
\text { Ñupui y Jahaveré, denuncian amenazas y atentado con arma } \\
\text { de fuego en el marco de los intentos de desalojo que sufren por } \\
\text { la expansión de emprendimientos y estancias turísticas. }\end{array}$ \\
\hline $\begin{array}{l}\text { Organizaciones de la } \\
\text { agricultura familiar } \\
\text { realizaron un } \\
\text { "Verdurazo" en Plaza } \\
\text { de Mayo }\end{array}$ & $\begin{array}{l}\text { Buenos } \\
\text { Aires } \\
\text { (CABA) }\end{array}$ & 09 & $\begin{array}{l}\text { La Unión de Trabajadores de la Tierra (UTT) se manifestó } \\
\text { por la defensa de la agricultura familiar con una acción de } \\
\text { entrega de } 20 \text { mil kilos de verdura en Plaza de Mayo } \\
\text { ("verdurazo"). }\end{array}$ \\
\hline $\begin{array}{l}\text { Consejo de Agricultura } \\
\text { Familiar, Campesina e } \\
\text { Indígena }\end{array}$ & $\begin{array}{l}\text { Buenos } \\
\text { Aires } \\
\text { (CABA) }\end{array}$ & 10 & $\begin{array}{l}\text { Movilización ante el Ministerio de Agroindustria, para } \\
\text { reclamar un conjunto de puntos por la grave situación del } \\
\text { sector y contra el vaciamiento de las políticas públicas para el } \\
\text { mismo. }\end{array}$ \\
\hline $\begin{array}{l}\text { Comunidades } \\
\text { denuncian al gobierno } \\
\text { provincial por quitarles } \\
\text { sus tierras }\end{array}$ & $\begin{array}{l}\text { Reserva } \\
\text { Grande } \\
\text { Chaco }\end{array}$ & 10 & $\begin{array}{l}\text { Comunidades de los 'pueblos Mocoví, Wichí y Qom } \\
\text { (Comandancia Frías, Fuerte Esperanza y Nueva Pompeya) } \\
\text { denuncian que el gobierno de Chaco pretende "robarles" } 100 \\
\text { mil hectáreas de la zona llamada "Reserva Grande" en el } \\
\text { Impenetrable. }\end{array}$ \\
\hline $\begin{array}{l}\text { Organizaciones } \\
\text { mapuches y de } \\
\text { derechos humanos } \\
\text { repudian al gobierno } \\
\text { nacional y rechazan } \\
\text { actividades petroleras }\end{array}$ & $\begin{array}{l}\text { Provincias } \\
\text { Patagónicas }\end{array}$ & 12 & $\begin{array}{l}\text { Más de cien organizaciones mapuches de Rio Negro, } \\
\text { Neuquén, Chubut y ONGs de derechos humanos (Amnistía } \\
\text { Internacional, SERPAJ, CELS, AADI), denuncian } \\
\text { "persecución al pueblo mapuche" y repudian las acciones del } \\
\text { gobierno nacional y al gobernador de la provincia de Chubut } \\
\text { y el incumplimiento de sus reivindicaciones territoriales. }\end{array}$ \\
\hline
\end{tabular}

Fuente: elaboración propia en base a relevamiento en diarios nacionales y provinciales, agencias de noticias, y comunicados de organizaciones sociales. 